Original Research Article

\title{
An evaluation of knowledge, attitude and practice of pharmacovigilance among interns in a tertiary care teaching hospital of North Maharashtra
}

\author{
Kiran Prabhakar Vakade ${ }^{1}$, Vijayaprasad M. Sangisetti ${ }^{1}$, Mitali V. Binayke ${ }^{2}$, \\ Vijaykumar N. Abhavathi ${ }^{1}$, Bana Bihari Nayak ${ }^{1}$
}

${ }^{1}$ Department of Pharmacology, ${ }^{2} 2^{\text {nd }}$ Year MBBS student, DVVPF's Medical College, Ahmednagar, Maharashtra, India

Received: 25 October 2016 Accepted: 02 November 2016

*Correspondence to:

Dr. Kiran Prabhakar Vakade, Email: dr.kiran84@gmail.com

Copyright: (C) the author(s), publisher and licensee Medip Academy. This is an openaccess article distributed under the terms of the Creative Commons Attribution NonCommercial License, which permits unrestricted noncommercial use, distribution, and reproduction in any medium, provided the original work is properly cited.

\begin{abstract}
Background: Adverse Drug Reactions (ADRs) are considered as one of the leading cause throughout the world resulting in significant increase in mortality and morbidity, therefore its monitoring is very essential in today's practice of medicine. Spontaneous reporting of ADRs have played a major role in the detection of unsuspected, serious and unusual ADRs previously undetected during the phases of clinical trials. Under-reporting of ADRs is considered as one of the major hurdle for the success of pharmacovigilance. Aims and objectives were to assess the knowledge, attitude and practice of pharmacovigilance among interns in a tertiary care teaching hospital.

Methods: A cross sectional, observational, questionnaire based study was carried out using a predesigned Knowledge Attitude Practice (KAP) questionnaire. Study was conducted after the permission of Institutional Ethical Committee (IEC). The study included 100 interns who had completed at least ten months of their internship. The KAP questionnaire was assessed and analyzed and data was presented as percentages.

Results: On an average only $31.17 \%$ interns answered correctly related with knowledge about pharmacovigilance. $88.63 \%$ interns agreed that ADRs reporting is necessary. According to $85.22 \%$ interns, pharmacovigilance must be taught in details to healthcare professionals. Only $34.09 \%$ had ever seen the ADR reporting form. Only $17.04 \%$ interns had knowledge about how to report ADR?

Conclusions: Our study revealed that there was lack of awareness related with knowledge, attitude and practice of pharmacovigilance among the interns. There is need of implementation of pharmacovigilance awareness programs for undergraduates.
\end{abstract}

Keywords: Adverse drug reaction, Pharmacovigilance, Spontaneous reporting

\section{INTRODUCTION}

Adverse drug reactions (ADRs) are considered as one of the important cause of morbidity and mortality. ${ }^{1}$ According to World Health Organization (WHO), ADR is defined as 'any noxious, unintended and undesired effect of the drug that occurs at doses used for prophylaxis, diagnosis or cure of a disease. ${ }^{2}$

Pharmacovigilance is defined as 'science and activities relating to the detection, assessment, understanding and prevention of adverse effects or any other drug related problems. ${ }^{2}$ Spontaneous reporting system is considered as backbone of pharmacovigilance. It plays major role in the detection of unsuspected, serious and unusual ADRs which could not be detected during the clinical trial phases. ${ }^{3}$ However major hurdle in the complete success of pharmacovigilance programme is underreporting of the ADRs. ${ }^{4}$

In a country like India, with a large population and vast diversity, implementation of standard pharmacovigilance 
programme is very necessary. Under reporting of ADRs is very common in India as compare to other countries. ${ }^{5}$ This underreporting may delay the detection of serious ADRs and definitely have major negative impact on the public health. Various studies have shown that inadequate knowledge about pharmacovigilance among healthcare professionals as well as their attitude towards pharmacovigilance mainly responsible for underreporting of ADRs. ${ }^{6-11}$

Due to under reporting of ADRs, assessment of awareness of pharmacovigilance is very important.

\section{METHODS}

It was a cross sectional, observational, questionnaire based study. The study was conducted at a tertiary care hospital of North Maharashtra after the permission from Institutional Ethical Committee (IEC). The study was conducted among 100 interns who had completed at least 10 months of their internship programme.

The questionnaire was made to evaluate the Knowledge Attitude Practice (KAP) of pharmacovigilance among the interns. The KAP questionnaire was obtained from the previous studies. ${ }^{12-16}$ The KAP questionnaires consisted of total 28 questions. Out of which 13 related with the knowledge, 9 related with the attitude and 6 related with the practice of pharmacovigilance.

The questionnaires were distributed among the interns to fill up the answers and 30 min of time duration was given for fill up the answer.

After the completion of the study, analysis of the data was done by using Microsoft excels and the results were formulated in the form of percentage.

\section{RESULTS}

Only 88 out of 100 interns filled and returned the questionnaire within the stipulated time frame. Response rate of the interns was found to be $88 \%$.

The KAP questionnaire consisted of total 28 questions. Out of which 13 related with knowledge, 9 related with attitude and 6 related with practice of pharmacovigilance.

\section{Analysis of knowledge related questions}

Only $34.09 \%$ interns answered correctly for the definition of pharmacovigilance while $44.31 \%$ interns were aware of the purpose of pharmacovigilance. $26.13 \%$ interns were aware of the location of international ADR monitoring center while $51.13 \%$ interns had knowledge about the regulatory body involved in the regulating ADR in India. Only $26.13 \%$ interns were aware about the phase of clinical trial in which rare adverse effects commonly found. Only $39.77 \%$ interns found to have knowledge related with the 'WHO online database' for reporting ADR. 32.95\% interns had knowledge about the order of ADR report submission. $36.36 \%$ interns answered correctly about the chairman of pharmacovigilance program in India.

Table 1: Questions related with knowledge of pharmacovigilance.

\begin{tabular}{|lll|}
\hline No. & $\begin{array}{l}\text { Questions related with knowledge } \\
\text { of pharmacovigilance }\end{array}$ & $\begin{array}{l}\text { \% of } \\
\text { correct } \\
\text { response }\end{array}$ \\
\hline 1 & Definition of pharmacovigilance & 34.09 \\
\hline 2 & Purpose of pharmacovigilance & 44.31 \\
\hline 3 & What pharmacovigilance incudes? & 32.50 \\
\hline 4 & $\begin{array}{l}\text { Where the international centre for } \\
\text { ADR monitoring is located? }\end{array}$ & 26.13 \\
\hline 5 & $\begin{array}{l}\text { Which regulatory body responsible } \\
\text { for monitoring ADRs in India? }\end{array}$ & 51.13 \\
\hline 6 & $\begin{array}{l}\text { A serious adverse event in India } \\
\text { should be reported to the regulatory } \\
\text { body within how many days? }\end{array}$ & 32.95 \\
\hline 7 & $\begin{array}{l}\text { Rare ADR usually identified in } \\
\text { which phase of clinical trial? }\end{array}$ & 26.13 \\
\hline 8 & $\begin{array}{l}\text { Which is the 'WHO online database' } \\
\text { used for reporting ADRs? }\end{array}$ & 39.77 \\
\hline 9 & $\begin{array}{l}\text { According to Wills and Brown, } \\
\text { ADRs are classified into how many } \\
\text { types? }\end{array}$ & 4.54 \\
\hline 10 & \begin{tabular}{l} 
Which type of ADR is common? \\
\hline 11
\end{tabular} & $\begin{array}{l}\text { What is the order of ADR } \\
\text { submission? }\end{array}$ \\
\hline 12 & $\begin{array}{l}\text { Who is the chairman of } \\
\text { pharmacovigilance programme in } \\
\text { India? }\end{array}$ & $\begin{array}{l}\text { ADR reporting forms are } \\
\text { periodically reviewed by whom? }\end{array}$ \\
\hline & \begin{tabular}{l}
36.86 \\
\hline 13
\end{tabular} \\
\hline
\end{tabular}

From Table 1, on an average only $31.17 \%$ interns correctly answered the questions related with knowledge about pharmacovigilance.

\section{Analysis of attitude related questions}

About $88.63 \%$ interns agreed that ADR reporting is necessary. According to $85.22 \%$ interns, pharmacovigilance must be taught in detail to healthcare professionals. $45.45 \%$ interns came across the article related with adverse drug reaction during their internship programme while only $38.64 \%$ interns agreed that reporting of adverse drug reaction is an obligation to them. $34.09 \%$ interns were aware about the existence of pharmacovigilance programme in India. According to $34.09 \%$ interns, 'A single unreported case may not affect ADR database' is the factor which discourage them from reporting ADR while according to $27.27 \%$, 'lack of time' is the factor which discourage them from reporting ADR. 
Table 2: Questions related with attitude towards pharmacovigilance.

\begin{tabular}{|lll|}
\hline No & Questions related with attitude towards pharmacovigilance & $\begin{array}{c}\text { of correct } \\
\text { response }\end{array}$ \\
\hline 1 & Is it necessary to report adverse drug reaction? & 88.63 \\
\hline 2 & Should pharmacovigilance be taught in detail to healthcare professionals? & 85.22 \\
\hline 3 & Have you read any article about adverse drug reaction? & 45.45 \\
\hline 4 & Is it necessary to establish ADR monitoring center in every hospital? & 46.59 \\
\hline 5 & Can a nonmedical person report to a nearby Healthcare Professional? & 60.23 \\
\hline 6 & Do you think reporting of adverse reaction is an obligation to you? & 38.64 \\
\hline 7 & Do you know regarding the existence of a National Pharmacovigilance Programme in India? & 34.09 \\
\hline 8 & Are you aware of the term of pharmacovigilance? & 84.09 \\
\hline & Most important factor which discourages you from reporting ADR? & 22.73 \\
\hline & A. Non - remuneration for reporting & 27.27 \\
\hline & B. Lack of time to report ADR & 34.09 \\
& C. A single unreported case may not affect ADR database & 15.91 \\
\hline
\end{tabular}

Table 3: Questions related with practice of pharmacovigilance.

\begin{tabular}{|lll|}
\hline No & Questions related with practice of pharmacovigilance & $\begin{array}{l}\text { of correct } \\
\text { response }\end{array}$ \\
\hline 1 & $\begin{array}{l}\text { Have you ever experienced adverse drug reaction in the patient during your internship training } \\
\text { programme? }\end{array}$ & $50 \%$ Yes \\
\hline 2 & Have you ever reported ADR to pharmacovigilance centre? & $2.27 \%$ Yes \\
\hline 3 & Have you ever seen the ADR reporting form? & $34.09 \%$ \\
\hline 4 & Have you got the training on 'how to report Adverse Drug Reaction? & $17.04 \%$ \\
\hline 5 & $\begin{array}{l}\text { Which of the following methods is commonly employed by the healthcare professional to monitor } \\
\text { adverse drug reactions of new drugs once they are launched in the market }\end{array}$ & 30.68 \\
\hline 6 & Is there any pharmacovigilance committee in your Institute? & 21.59 \\
\hline
\end{tabular}

\section{Analysis of practice related questions}

$50 \%$ interns experienced adverse drug reaction in the patients during their internship training programme but only $2.27 \%$ interns reported to pharmacovigilance centre. $34.09 \%$ interns were aware about ADR reporting form. Only $17.04 \%$ interns got the training on 'how to report ADR?' Only $21.59 \%$ interns were aware about the pharmacovigilance committee in their institute.

\section{DISCUSSION}

Pharmacovigilance is considered as one of the important post-marketing tools to provide the safety of pharmaceutical, herbals and related health products. Due to detection of ADRs in the post marketing studies, many drugs like cisapride, valdecoxib, sibutrabine, benoxaprofen, cerivastatin have been withdrawn from the market. $^{17-19}$

The spontaneous reporting system is considered as backbone of pharmacovigilance, however underreporting of ADRs is considered as most important hurdle for the success of pharmacovigilance. ${ }^{20}$ According to Hema NG et al, lack of proper knowledge and awareness about pharmacovigilance is considered as most important reason for the underreporting of adverse drug reactions. ${ }^{5}$

We conducted the study to find out awareness about knowledge, attitude and practice of pharmacovigilance among interns of tertiary care hospital of North Maharashtra. In our study we found inadequate awareness about pharmacovigilance among interns. Only $31.17 \%$ interns answered correctly about knowledge related questions of pharmacovigilance. Good pharmacovigilance knowledge is very important for practicing pharmacovigilance. Though $88.63 \%$ interns agreed about necessity of reporting ADR, only $17.04 \%$ interns had knowledge about 'how to report ADR?'

Study conducted by Rehan HS et al at a tertiary care hospital, New Delhi showed that the students and prescribers needed further improvement in their knowledge, attitude and practices. $^{21}$ A similar study conducted by Desai CK et al at a tertiary care hospital, Ahmedabad, found under reporting and lack of knowledge about the reporting system among the prescribers. ${ }^{22}$

A cross sectional, questionnaire based, multi-centric study conducted by Vora MB et al at six different 
colleges in Gujarat found overall low awareness about pharmacovigilance among undergraduate medical students. ${ }^{23}$ Also an awareness on the reporting systems was found very low amongst the resident doctors in a study conducted by Gupta $\mathrm{P}$ et al at two government teaching hospitals of Maharashtra. ${ }^{24}$ Inadequate knowledge on pharmacovigilance among resident doctors have been found in similar studies conducted in Nigeria and France. ${ }^{25,26}$

A study which was conducted at a tertiary care hospital of Nepal have also found low KAP scores among prescribers and it suggested the need for educational interventions. ${ }^{27}$ Study conducted by Muraraiah $\mathrm{S}$ et al have demonstrated that educational interventions can increase the awareness of pharmacovigilance among the health care professionals. ${ }^{28}$

\section{Limitations of the study}

One of the limitations of our study was small number size. It is recommended that similar kind of studies must be conducted in other health professionals.

\section{CONCLUSION}

In our study we found inadequate knowledge about pharmacovigilance, so it is recommended to implement educational intervention programme to improve knowledge of future students, as well as pharmacovigilance should be included in the curriculum of medical students.

\section{ACKNOWLEDGEMENTS}

We wish to thank all the interns who have participated in this study and also management of our tertiary care hospital for their constant support and encouragement.

Funding: No funding sources Conflict of interest: None declared

Ethical approval: The study was approved by the Institutional Ethics Committee

\section{REFERENCES}

1. Lazarou J, Pomeranj BH, Corey PN. Incidence of ADR in prospective studies in hospitalized patients: a meta-analysis of prospective studies. JAMA.1998;279:1000-5.

2. World Health Organization. Safety of Medicines. A guide to detecting and reporting adverse drug reactions. Geneva, Switzerland: World Helath Organization. 2002.

3. Kumari S, Saxsena A, Senthikumar P. Evaluation of knowledge, awareness and attitude practice among nurses inpharmacovigilance at tertiary care teaching hospital in Delhi. 2015;4(1),76-86.

4. Lopez- Gonzalez E, Herdeiro MT, Figueiras A. Determinants of under-reporting of adverse drug reactions: A systemic Review. Drug Saf. 2009;32:1931.

5. Hema NG, Bhuvana KB, Sangeetha. Pharmacovigilance: The extend of awareness among the final year students, interns and postgraduates in a government teaching hospital. J Clin Diagn Res. 2012;6(7):1248-53.

6. Figueiras A, Tato F, Fontainas J, Gestal-Otero JJ et al: Influence of physicians' attitudes on reporting adverse drug events: A casecontrol study. Medical Care. 1999;37(8):809-14.

7. Williams D, Feely J. Underreporting of adverse drug reactions: attitudes of Irish doctors. Irish Journal of Medical Science. 1999;168:257-61.

8. Perlik F, Slanar O, Smid M, Petracek J. Attitude of Czech physicians to adverse drug reaction reporting, European Journal of Clinical Pharmacology. 2002;58:367-9.

9. Belton KJ, Lewis SC, Payne S, Rawlins MD. Attitudinal survey of adverse drug reaction reporting by medical practitioners in the United Kingdom, British Journal of Clinical Pharmacology. 1995;39:223-6.

10. Hasford J, Goettler M, Munter KH, MullerOerlinghausen B. Physicians' knowledge and attitudes regarding the spontaneous reporting system for adverse drug reactions, Journal of Clinical Epidemiology. 2002;55:945-50.

11. Herdeiro MT, Figueiras A, Poló nia J, Gestal- Otero JJ. Physicians' attitudes and adverse drug reaction reporting: a case control study in Portugal, Drug Saf. 2005;28:825-33.

12. Upadhyaya P, Seth V, Moghe VV, Sharma M, Ahmed M. Knowledge of adverse drug reaction reporting in the first year postgraduate doctors in a medical college. Ther Clin risk Manage. 2012;8:30712.

13. Ramesh A. Identifying the reasons for under reporting of ADR: A cross sectional survey. Res J Pharm Biol Chem Sci. 2012;3:1379-86.

14. Hardeep, Bajaj JK, Kumar R. A survey on the knowedge, attitude and the practice of pharmacovigilnce among the health care professionals in a teching hospital in northern India. $\mathbf{J}$ Clin Diagn Res. 2013;7:97-9.

15. Gupta P, Udupa A. Adverse drug reaction reporting and pharmacovigilance. Knowledge, attitude and perceptions among the resident doctors. J Pharm Sci Res. 2011;3:1064-9.

16. Desai CK, Iyer G, Panchal J, Shah S, Dikshit RK. An evaluation of knowledge, attitude and practice of adverse drug reaction reporting among prescribers at a tertiary care hospital. Perspect Clin Res. 2011;2:129-36.

17. The Safety of Medicines in Public Health Programmes: Pharmacovigilance, an Essential Tool World Health Organization. 2006.

18. Ninan B, Wertheimer AI Withdrawing Drugs in the USA versus Other Countries. Innovations in pharmacy. 2012;3(3):1-12. 
19. Williams G. Withdrawal of sibutramine in Europe, BMJ. 2010;340:c824.

20. Khan TM. Challenges to pharmacy and pharmacy practice in Pakistan. J Australasian Med. 2011;4:2305.

21. Rehan HS, Vasudev K, Tripathi CD. Adverse drug reaction monitoring: the knowledge, attitude and the practices of the medical students and the prescribers. Natl Med J India. 2002;15(1):24-6.

22. Desai CK, Iyer G, Panchal J, Shah S, Dikshit RK. An evaluation of the knowledge, attitude and the practice of adverse drug reaction reporting among the prescribers at a tertiary care hospital. Perspective in Clinical Research. 2011;2(4):129-35.

23. Vora MB, Paliwal NP, Doshi VG, Barvaliya MJ, Tripathi CB. Knowledge of adverse reactions and Pharmacovigilance activity among undergraduate medical students of Gujarat. Int J Pharm Sci Res. 2012;3(5):1511-5.

24. Gupta P, Udupa A. Adverse drug reaction reporting and pharmacovigilance: knowledge, attitudes and perceptions among the resident doctors. J. Pharm Sci Res. 2011;3:1064-69.

25. Ohaju-Obodo, JO, Iribhog be OI. The extent of pharmacovigilance among the resident doctors in the
Edo and the Lagos states of Nigeria. Pharmacoepidemiology and Drug Safety. 2010;19:191-95.

26. Graille V, Lapeyre-Mestre M, Mon Tadric JL. Drug vigilance: An opinion survey which was conducted among the residents of a university hospital. Therapie. 1994 Sep-Oct;49(5):451-54.

27. Subish P, Izham MM, Mishra P. Evaluation of the knowledge, attitudes and the practices on adverse drug reactions and pharmacovigilance among the health care professionals in a Nepalese hospital: A preliminary study. The Int J of Pha. 2008;6(1):15312976.

28. Muraraiah S, Rajrathana K, Sreedhar D, Basavalingu D, Jayanti CR. A questionnaire study which was done to assess the knowledge, attitude and the practice of pharmacovigilance in a paediatric tertiary care centre. J Chem Pharm Res. 2011;3(6):416-22.

Cite this article as: Vakade KP, Sangisetti VM, Binayke MV, Abhavathi VN, Nayak BB. An evaluation of knowledge, attitude and practice of pharmacovigilance among interns in a tertiary care teaching hospital of North Maharashtra. Int J Basic Clin Pharmacol 2016;5:2321-5. 